\title{
Production of biologically active human lymphotactin (XCL1) by Lactococcus lactis
}

\author{
Laura M. Zavala-Flores · Julio Villatoro-Hernandez • Anali Gamez-Escobedo • \\ Moisés Franco-Molina · Blanca R. Rangel-Colmenero · Arnulfo Villanueva-Olivo • \\ Yolanda Gutierrez-Puente · Roberto Montes de Oca-Luna · Jesús Valdés-Flores • \\ Odila Saucedo-Cardenas
}

Received: 18 August 2008/Revised: 12 September 2008/Accepted: 19 September 2008/Published online: 16 October 2008 (C) Springer Science+Business Media B.V. 2008

\begin{abstract}
Lymphotactin-XCL1 is a chemokine produced mainly by activated $\mathrm{CD} 8+\mathrm{T}$-cells and directs migration of $\mathrm{CD} 4+$ and $\mathrm{CD} 8+$ lymphocytes and natural killer (NK) cells. We expressed human lymphotactin (LTN) by the lactic-acid bacterium Lactococcus lactis. Biological activity of LTN was
\end{abstract}

Laura M. Zavala-Flores and Julio Villatoro-Hernandez have contributed equally to this work.

L. M. Zavala-Flores · J. Villatoro-Hernandez ·

B. R. Rangel-Colmenero · A. Villanueva-Olivo

R. M. de Oca-Luna · O. Saucedo-Cardenas

Departamento de Histología, Facultad de Medicina,

Universidad Autónoma de Nuevo León (UANL),

Monterrey, NL, Mexico

A. Gamez-Escobedo · M. Franco-Molina

Departamento de Microbiología e Inmunología, Universidad Autónoma de Nuevo León (UANL),

San Nicolas de los Garza, NL, Mexico

Y. Gutierrez-Puente

Departamento de Bioquímica, Facultad de Ciencias Biológicas, Universidad Autónoma de Nuevo León

(UANL), San Nicolas de los Garza, NL, Mexico

J. Valdés-Flores

Departamento de Bioquímica, CINVESTAV, Apartado Postal 14-740, Mexico, DF 07360, Mexico

O. Saucedo-Cardenas ( $\square$ )

División de Genética, Centro de Investigación Biomédica del Noreste, Instituto Mexicano del Seguro Social (IMSS), Col. Independencia, Monterrey, NL 64720, Mexico

e-mail: odilam@hotmail.com confirmed by chemo-attraction of human T-cells by chemotaxis demonstrating, for the first time, how this chemokine secreted by a food-grade prokaryote retains biological activity and chemoattracts $\mathrm{T}$ lymphocytes. This strain thus represents a feasible well-tolerated vector to deliver active LTN at a mucosal level.

Keywords Biological activity - Lactococcus lactis . Lymphotactin · Secretion

\section{Introduction}

Chemokines, the largest family of cytokines, cause leukocyte mobilization through chemotaxis at sites of antigenic challenge or lesions. Lymphotactin (LTN), the only member of the $\mathrm{C}$ subfamily of chemokines, is mainly secreted by activated $\mathrm{T}$ lymphocytes and it chemoattracts CD4+ and CD8+ lymphocytes as well as natural killer (NK) cells (Hedrick et al. 1997). This chemokine plays an important role in maintaining the integrity of the epithelium and in mucosal immune responses. Previous studies revealed that the intranasal administration of LTN resulted in the enhancement of the mucosal and systemic antibody response through help provided by Th1- and Th2-type cells (Lillard et al. 1999).

Moreover, this chemokine has some antitumor activity and, when expressed in engineered myeloma 
cells, resulted in tumor regression in mice. This effect was assumed to be mediated by CD4+ and CD8+ cells and neutrophils expressing the XCR1 receptor, the receptor for LTN (Cairns et al. 2001). Another approach to use LTN as an enhancer of immune responses was with the manipulation of dendritic cells (DCs) for the expression of this chemokine. The administration of the DCs expressing LTN caused a potent adjuvant effect for peptide delivery causing specific antitumor immunity in mice (Cao et al. 1998).

Our goal was to create an innocuous and safe vector to produce, but mostly to deliver, LTN in vivo. In recent years, the lactic-acid bacterium L. lactis has been used as an efficient vector to express heterologous proteins of medical and therapeutic interest (Wells and Mercenier 2008). The intranasal immunization with strains of this food-grade bacterium has resulted in the generation of specific humoral and cytotoxic immune responses against infectious and chronic diseases (Braat et al. 2006; Hanniffy et al. 2007; Wells and Mercenier 2008). Because of these promising results using this microorganism, we genetically manipulated a strain of L. lactis to express and secrete human lymphotactin (huLTN). Here we demonstrate how this L. lactis-secreted LTN remains biologically active and able to chemoattract $\mathrm{T}$ lymphocytes by chemotaxis. This is the first report that demonstrates the biological activity of huLTN secreted by a food-grade lactic acid bacterium.

\section{Materials and methods}

Bacterial strains and growth conditions

Lactococcus lactis NZ9000 (Kuipers et al. 1997) was grown aerobically in M17 medium (DIFCO) supplemented with $1 \%$ glucose (GM17) at $30^{\circ} \mathrm{C}$ without agitation. Escherichia coli DH5 $\alpha$ was grown in LuriaBertani (LB) medium at $37^{\circ} \mathrm{C}$ with aeration and vigorous shaking. Unless otherwise indicated, construction were first established in E. coli and then transferred to L. lactis by electrotransformation (Holo and Nes 1989). Clones were selected by addition of $100 \mu \mathrm{g}$ ampicillin $/ \mathrm{ml}$ or $10 \mu \mathrm{g}$ chloramphenicol $/ \mathrm{ml}$ for E. coli and $10 \mu \mathrm{g}$ chloramphenicol/ml for L. lactis. PCR was done using Vent DNA polymerase (New England Biolabs) according to the manufacturer's instructions using a programmable thermal controller.
Harvest and culture of macrophages

Human macrophages were isolated from freshly drawn blood by using Ficoll-Hypaque (Histopaque1077, Sigma). The layer of mononuclear cells was recovered, washed with PBS, and cultured for $3 \mathrm{~h}$ in RPMI 1640 medium supplemented with 10\% (v/v) heat-inactivated fetal bovine serum (FBS) and then incubated at $37^{\circ} \mathrm{C}$ in a $5 \% \quad \mathrm{CO}_{2}$. Adherent cells (macrophages) were recovered by removing the culture medium. Macrophages were seeded into 6-well plates (Costar) at $5 \times 10^{6}$ cells $/ \mathrm{ml}$ in complete RPMI-1640 medium (10\% v/v heat-inactivated FBS, $1 \%$ penicillin-streptomycin solution, and $1 \%$ HEPES buffer) stimulated with $20 \mathrm{mg}$ lipopolysaccharides/ml (LPS B from E. coli 026:B6, Sigma) and incubated at $37^{\circ} \mathrm{C}$ in a $5 \% \mathrm{CO}_{2}$ for $5 \mathrm{~h}$.

Human cDNA preparation

The total RNA from $5 \times 10^{6}$ cells of LPS-stimulated human macrophages was isolated using TRizol reagent (Gibco) according to the manufacturer's instructions. The concentration and integrity of RNA was determined by measuring absorbance at $260 \mathrm{~nm}$ and analyzed by formaldehyde-agarose gel electrophoresis. The first strand cDNA was synthesized from $1 \mu \mathrm{g}$ total RNA by SuperscriptTM II reverse transcriptase (Gibco) and oligo (dT) 12-18 primer.

Protein extraction from L. lactis

Cell and cell-free medium fractions were prepared separately. Samples were processed from $1.35 \mathrm{ml}$ of cultures of L. lactis. Cell pellets were obtained by centrifugation at $21000 \mathrm{~g}$ at $4^{\circ} \mathrm{C}$ for $5 \mathrm{~min}$. Cell pellets were then resuspended in $100 \mu \mathrm{l}$ lysis buffer containing 25\% (w/v) sucrose, $1 \mathrm{mM}$ EDTA, $50 \mathrm{mM}$ Tris/HCl, $\mathrm{pH} 8.0$, lysozyme $(10 \mathrm{mg} / \mathrm{ml})$ complemented with $1 \mathrm{mM}$ PMSF to avoid proteolysis and $10 \mathrm{mM}$ DTT and incubated at $37^{\circ} \mathrm{C}$ for $1 \mathrm{~h}$. Samples were kept at $-20^{\circ} \mathrm{C}$ before loading onto gel.

The cell-free medium samples were treated with $1 \mathrm{mM}$ PMSF and $10 \mathrm{mM}$ DTT to avoid proteolysis. Proteins were precipitated adding $150 \mu \mathrm{l}$ of $100 \%$ trichloroacetic acid (TCA) to $1.35 \mathrm{ml}$ cell-free medium (TCA at $10 \% \mathrm{w} / \mathrm{v}$ ) and incubated on ice for $10 \mathrm{~min}$ followed by centrifugation at $21000 \mathrm{~g}$ at 
$4^{\circ} \mathrm{C}$ for $15 \mathrm{~min}$. The pellet was resuspended in $50 \mu \mathrm{l}$ of $50 \mathrm{mM} \mathrm{NaOH}$ and $50 \mu \mathrm{l}$ of $2 \times$ SDS-PAGE loading buffer $(100 \mathrm{mM}$ Tris/HCl, pH 6.8, $200 \mathrm{mM}$ DTT, $4 \% \mathrm{v} / \mathrm{v}$ SDS, $0.1 \%$ Bromophenol Blue, and $10 \% \mathrm{v} / \mathrm{v}$ glycerol).

SDS-PAGE and western blotting

Samples were electrophoresed in $12 \%$ polyacrylamide gels. Immunodetection was done using polyclonal anti-lymphotactin (Santa Cruz) as a primary antibody and protein-G horseradish-peroxidase conjugate (BioRad). SuperSignal West Pico Chemiluminescent Substrate (Pierce) was used as recommended by the suppliers.

Lymphocyte culture

Human peripheral blood lymphocytes were isolated from donor whole blood by centrifugation on FicollHypaque (Histopaque-1077 Sigma) according to manufacturer's instructions. After washing three times with RPMI 1640 medium (Gibco), the cells were cultured in RPMI 1640 medium supplemented with $10 \%$ human serum (Sigma) and $200 \mathrm{U}$ human interleukin 2/ml (Santa Cruz Biotechnologies) at $37^{\circ} \mathrm{C}$ in a $5 \% \mathrm{CO}_{2}$ for 12 days. Cell density was kept between 1 and $3 \times 10^{6}$ cells $/ \mathrm{ml}$.

\section{Chemotaxis assay and flow cytometry}

Cell migration was measured in $5 \mu \mathrm{m}$ diameter pore-size cellulose-nitrate membranes (Whatman) using a Boyden chemotaxis chamber. Cell-free medium from wild type and recombinant L. lactis cultures were sterilized by filtration through a $0.22 \mu \mathrm{m}$ filter (Millex, Millipore) and loaded into the lower compartment of Boyden chamber for chemotaxis. Lymphocytes ( $10^{5}$ cells) in RPMI 1640 medium were loaded into the upper compartment. Chemotaxis was allowed to occur for $1 \mathrm{~h}$ at $37^{\circ} \mathrm{C}$. Migrated cells were counted by a fluorescenceactivated cell-sorting (FACS) flow cytometer. The aqueous phase from the lower compartment of chambers was gently recovered and centrifuged. The resulting cell pellet was suspended in PBS and incubated for 10 min with human anti-CD3 FITC (BD Biosciences Pharmingen, San Diego, USA), washed with PBS, and counted with an FACS sorting cytometer. All chemotaxis assays were done in triplicate. Complement-activated serum was prepared from fresh human serum by addition of $25 \mathrm{mg}$ zymosan (Sigma) per $\mathrm{ml}$ serum and incubated at $37^{\circ} \mathrm{C}$ for $1 \mathrm{~h}$. Statistical analysis was done using the Tukey test.

\section{Results and discussion}

Construction of an inducible system for LTN secretion by L. lactis

Lymphotactin is a chemokine produced by leukocytes upon stimulation. To obtain a DNA sequence coding for huLTN, we first constructed a cDNA from human macrophages stimulated with LPS. The DNA sequence coding for the mature moiety was PCR amplified from this human cDNA with the following oligonucleotides: LptnHP9rw: (5'-TATGCATCAGT AGGGAGTGAAATCTCA-3 ${ }^{\prime}$ ) and reverse primer (LptnHLBfw: 5'-CTAGCCAGTCAGGGTCACAGC TGT- $3^{\prime}$ ), which generated a NsiI restriction site (indicated in bold) to manipulate the fragment for future cloning. The $298 \mathrm{bp}$ amplicon was directly cloned into the pCR2.1 vector (Invitrogen) and named pCR2.1-huLTN.

For the generation of the plasmid responsible for regulation of expression and secretion of LTN in L. lactis, the plasmid pCR2.1-huLTN was digested with NsiI-EcoRI releasing the fragment coding for LTN and subcloned into the pSEC-E7 vector digested with the same enzymes. The final construct was named pSEC-huLTN. This strategy permitted the fusion in-frame of the DNA sequence coding for LTN with the signal peptide from the usp45 ( $\left.\mathrm{SP}_{\mathrm{Usp} 45}\right)$, the most secreted protein of L. lactis (van Asseldonk et al. 1990), and placed under the regulation of the well-characterized nisin-inducible promoter (PnisA) (Fig. 1).

Finally our construction was introduced into the L. lactis strain NZ9000 carrying the regulatory genes $n i s R$ and nisK (de Ruyter et al. 1996) by electrotransformation as previously described (Holo and Nes 1989). Recombinant strains carrying the final construct were selected by resistance to chloramphenicol and named NZSEC:huLTN. All plasmids were endonuclease-characterized and sequenced for DNA integrity. 


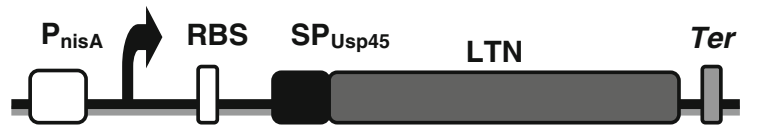

Fig. 1 Schematic representation of LTN expression system for production and secretion by L. lactis. The scheme represents the regulatory system to express huLTN by L. lactis, controlled by inducible promoter $\mathrm{P}_{\text {nis }}\left(\mathrm{P}_{\text {nis }}\right)$, and using the ribosome binding site (RBS) and signal peptide of the of Usp45 protein $\left(\mathrm{SP}_{\mathrm{usp} 45}\right)$. The final gray bar (from left to right) represents a rho-independent $\operatorname{trp} A$ transcription terminator. (Not to scale)

Secretion of LTN by L. lactis is efficient

To evaluate the functionality and efficiency of the system for secretion of LTN, three transformants (NZSEC:huLTN) were induced with nisin for just $1 \mathrm{~h}$ to allow LTN expression and then analyzed by Western blot using polyclonal anti-lymphotactin antibodies. Protein extractions were made separately for cell and cell-free medium fractions.

Western blot analysis of samples from the cell-free medium from the induced cultures revealed a single band of $10 \mathrm{kDa}$, the expected molecular mass of LTN, indicating that that protein corresponded to LTN secreted by L. lactis (Fig. 2). No degradation or incomplete forms of the LTN were detected, showing an efficient secretion of the chemokine by L. lactis. To evaluate the functionality of the inducible system and to determine if the system remained completely shutdown in the absence of the inducer (nisin), we analyzed samples from non-induced cultures of these same

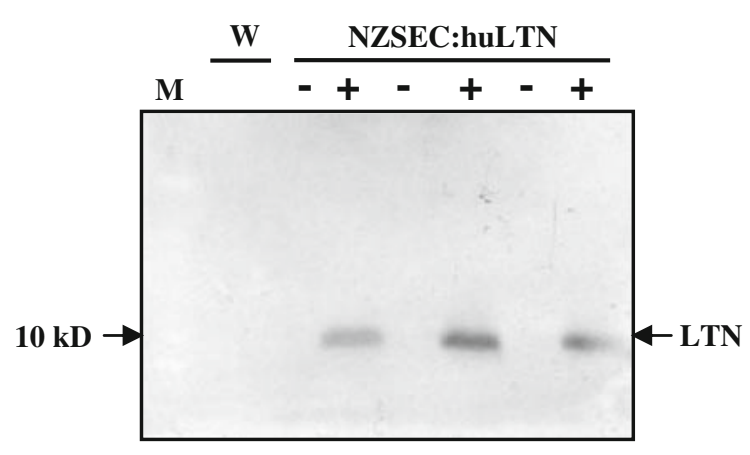

Fig. 2 Efficient secretion of huLTN by L. lactis. Three different clones from recombinant L. lactis (NZSEC:huLTN) were analyzed by Western blot for secretion of huLTN. Cell-free medium samples of induced $(+)$ and non-induced $(-)$ cultures. WT, cell-free medium from wild type strain. M, protein molecular marker recombinant strains. No signal was detected in any of the non-induced samples, showing how the expression of the LTN is strictly regulated by the nisin-inducible system, where in the absence of nisin, the expression of LTN is completely turned off (Fig. 2). No signal was detected in either of the cell fractions from induced and non-induced cultures (data not shown). Samples from the cell-free medium from wild-type L. lactis were included as controls. As expected, no signal for LTN was detected (Fig. 2).

\section{Secreted amount of LTN by L. lactis}

To estimate the relative amount of LTN secreted by L. lactis, cultures from recombinant NZSEC:huLTN at an $\mathrm{OD}_{600 \mathrm{~nm}}$ of 0.6 were induced for $1 \mathrm{~h}$ followed by protein extraction from the cell-free medium as before. Serial dilutions were compared against fixed amounts of human recombinant lymphotactin $(\mathrm{RnD}$ Systems) by western blot analysis. The undiluted extract in Fig. 3, which has the highest intensity, corresponds to protein precipitated from $675 \mu \mathrm{l}$ cell-free medium from an induced culture of NZSEC:huLTN. Analysis of band intensities with computer software (Phoretix 1D, Nonlinear dynamics) indicates that our recombinant L. lactis secretes at least $590 \mathrm{ng}$ of LTN per $\mathrm{ml}$ of culture. This result demonstrates how this strain of L. lactis is able to secrete more than $500 \mathrm{ng}$ huLTN protein in just $1 \mathrm{~h} / \mathrm{ml}$ of culture.

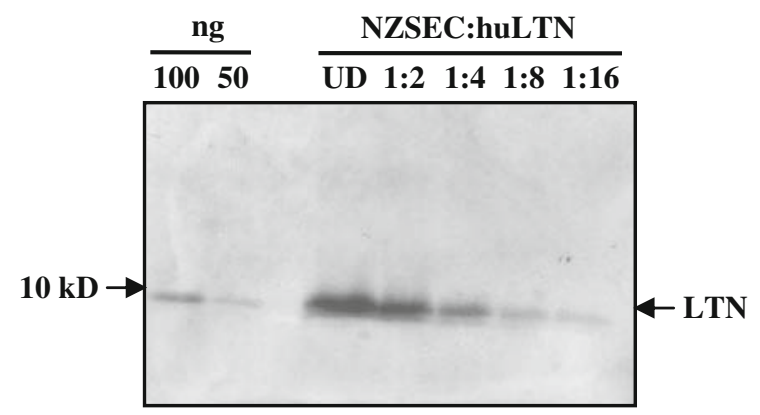

Fig. 3 Semiquantitative analysis of LTN secreted by L. lactis. Cultures of recombinant L. lactis (NZSEC:huLTN) grown were induced with $10 \mathrm{ng} / \mathrm{ml}$ of nisin for $1 \mathrm{~h}$. The cell-free medium samples were processed and serial dilutions from the total extract from 1:2 to 1:16 were prepared. Samples and two fixed amounts of pure recombinant LTN (50 and $100 \mathrm{ng}$ ) were analyzed by Western Blot using a specific anti-lymphotactin antibody. Undiluted sample (UD) represents the amount of LTN in $675 \mu \mathrm{l}$ from a $L$. lactis culture induced for $1 \mathrm{~h}$ 
Biological activity of L. lactis-secreted LTN

Lymphotactin is a glycosylated chemokine able to direct migration of $\mathrm{T}$ lymphocytes and NK cells (Dorner et al. 1997; Lillard et al. 1999). Because we achieved the expression of this LTN in L. lactis, our next step was to determine the biological activity of this L. lactis-secreted chemokine. We measured the ability to chemoattract human $\mathrm{T}$ lymphocytes by the L. lactis-secreted LTN in a chemotaxis assay. For this we added $10^{5}$ cells of activated T lymphocytes to the upper compartment of the chemotaxis chamber and cell-free medium from cultures of L. lactis to the bottom compartment. Chemotaxis was allowed to occur for $1 \mathrm{~h}$ at $37^{\circ} \mathrm{C}$ and then the attracted cells to the bottom of the chamber were recovered. After centrifugation, the cells were washed with PBS and incubated with human anti-CD3+ and counted with a FACS flow cytometer. The cell counts showed that the LTN present in medium from induced cultures of recombinant strain NZSEC:huLTN induced chemoattraction of more than 15,000 T cells (Fig. 4), indicating the ability of this chemokine secreted by a gram positive bacterium to chemoattract human $\mathrm{T}$ lymphocytes. The cell-free medium from a culture of wild-type L. lactis and PBS were used as negative controls and did not attract significant amounts of

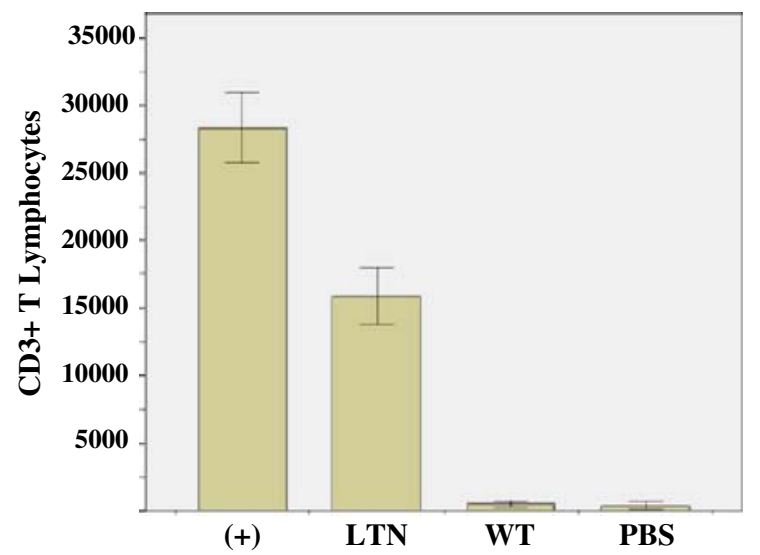

Fig. 4 Secreted LTN by L. lactis is biologically active. Chemotactic activity of LTN secreted by L. lactis was evaluated by chemotaxis of activated human $\mathrm{T}$ lymphocytes in Boyden chambers. After chemotaxis, attracted cells were counted by FACS analysis using an anti-CD3+ antibody. Complement activated human serum was used as a positive control and as negative controls cell-free medium from WT strain (WT) and PBS cells. Complement-activated serum was used as a positive control (Fig. 4).

These results demonstrate for the first time the expression and secretion of a $\mathrm{C}$ subfamily chemokine of human origin by L. lactis, biologically active, able to cause chemoattraction of human $\mathrm{T}$ lymphocytes (Fig. 4).

Antecedents have demonstrated the use of L. lactis as a biological vector to deliver antigens and cytokines at mucosal surfaces to cause humoral and cytotoxic immune responses (Wells and Mercenier 2008). Here we report a novel strain of $L$. lactis able to secrete a biologically active antitumor chemokine. This food-grade bacterium represents a feasible well-tolerated vector intended to be used in live organisms to deliver huLTN at a mucosal level.

Acknowledgements This work was supported by National Council of Science and Technology (CONACYT) of Mexico, Grant No. 47478 to Roberto Montes de Oca-Luna. Laura M. Zavala-Flores, Julio Villatoro-Hernandez and Blanca R. Rangel-Colmenero are $\mathrm{PhD}$ students and recipients of a scholarship from CONACYT of Mexico. Thanks to Dr. Ellis Glazier for editing this English-language text.

\section{References}

Braat H, Rottiers P, Hommes DW, Huyghebaert N, Remaut E, Remon JP, van Deventer SJ, Neirynck S, Peppelenbosch MP, Steidler L (2006) A phase I trial with transgenic bacteria expressing interleukin-10 in Crohn's disease. Clin Gastroenterol Hepatol 4:754-759

Cairns CM, Gordon JR, Li F, Baca-Estrada ME, Moyana T, Xiang J (2001) Lymphotactin expression by engineered myeloma cells drives tumor regression: mediation by CD4+ and CD8+ $\mathrm{T}$ cells and neutrophils expressing XCR1 receptor. J Immunol 167:57-65

Cao X, Zhang W, He L, Xie Z, Ma S, Tao Q, Yu Y, Hamada H, Wang J (1998) Lymphotactin gene-modified bone marrow dendritic cells act as more potent adjuvants for peptide delivery to induce specific antitumor immunity. J Immunol 161:6238-6244

de Ruyter PG, Kuipers OP, de Vos WM (1996) Controlled gene expression systems for Lactococcus lactis with the food-grade inducer nisin. Appl Environ Microbiol 62:3662-3667

Dorner B, Muller S, Entschladen F, Schroder JM, Franke P, Kraft R, Friedl P, Clark-Lewis I, Kroczek RA (1997) Purification, structural analysis, and function of natural ATAC, a cytokine secreted by CD8(+) T cells. J Biol Chem 272:8817-8823

Hanniffy SB, Carter AT, Hitchin E, Wells JM (2007) Mucosal delivery of a pneumococcal vaccine using Lactococcus lactis affords protection against respiratory infection. J Infect Dis 195:185-193 
Hedrick JA, Saylor V, Figueroa D, Mizoue L, Xu Y, Menon S, Abrams J, Handel T, Zlotnik A (1997) Lymphotactin is produced by NK cells and attracts both NK cells and T cells in vivo. J Immunol 158:1533-1540

Holo H, Nes IF (1989) High-frequency transformation, by electroporation, of Lactococcus lactis subsp. cremoris grown with glycine in osmotically stabilized media. Appl Environ Microbiol 55:3119-3123

Kuipers OP, de Ruyter PG, Kleerebezem M, de Vos WM (1997) Controlled overproduction of proteins by lactic acid bacteria. Trends Biotechnol 15:135-140
Lillard JW Jr, Boyaka PN, Hedrick JA, Zlotnik A, McGhee JR (1999) Lymphotactin acts as an innate mucosal adjuvant. J Immunol 162:1959-1965

van Asseldonk M, Rutten G, Oteman M, Siezen RJ, de Vos WM, Simons G (1990) Cloning of usp45, a gene encoding a secreted protein from Lactococcus lactis subsp. lactis MG1363. Gene 95:155-160

Wells JM, Mercenier A (2008) Mucosal delivery of therapeutic and prophylactic molecules using lactic acid bacteria. Nat Rev Microbiol 6:349-362 